\title{
Thermal properties of polymer compounds based on recycled polypropylene and polyethylene
}

\author{
A. G. Khusnullin' ${ }^{1}$, E. M. Zakharova ${ }^{1}$, A. A. Psyanchin ${ }^{\dagger, 1}$, V.P. Zakharov ${ }^{2}$ \\ †artps96@yandex.ru \\ ${ }^{1}$ Bashkir State University, Ufa, 450076, Russia \\ ${ }^{2}$ Ufa Federal Research Centre of the RAS, Ufa, 450054, Russia
}

\begin{abstract}
The relevance of the problem under study is due to an increase in the amount of polymer waste based on synthetic polymers, which determines the feasibility of its involvement in recycling in relation to thermoplastic polyolefins. A significant proportion of plastic waste falls on plastic products made of polypropylene, while the processed raw materials almost always contain a mixture of polypropylene with different polyethylene content. The aim of the work was to study the thermal characteristics of polymer compounds based on secondary polypropylene filled with high and low pressure polyethylene. The leading approach to the study of this problem is the use of methods of thermogravimetry and differential scanning calorimetry, which make it possible to identify patterns of changes in temperature and thermal characteristics of phase transitions, as well as thermal stability of polymer compounds. It is shown that the presence of two peaks of melting and crystallization on thermograms of differential scanning calorimetry of polypropylene-polyethylene mixtures indicates the incompatibility of polymers, while the polymer system is heterophase. In the presence of polyethylene, the crystallization rate of polypropylene changes, while its melting temperature decreases and the crystallization temperature increases compared to a pure polymer. Filling the compound with polyethylene of both low and high pressure reduces the rate of decomposition of secondary polypropylene and shifts the decomposition process of compounds to higher temperatures. The mass of the dry residue when heated to $400^{\circ} \mathrm{C}$ and $600^{\circ} \mathrm{C}$ for a polymer compound with low-pressure polyethylene is higher compared to high-pressure polyethylene. The materials of the article can be useful for the creation of polymer composites based on recycled polypropylene in the presence of polyethylene, as well as the development of technological modes of their processing.
\end{abstract}

Keywords: secondary polypropylene, low-pressure polyethylene, high-pressure polyethylene, differential scanning calorimetry, thermogravimetric analysis.

\section{Теплофизические свойства полимерных компаундов} на основе вторичного полипропилена и полиэтилена

\author{
Хуснуллин А. Г. ${ }^{1}$ Захарова Е. М. ${ }^{1}$, Псянчин А. А. ${ }^{\dagger, 1}$, Захаров В. П. ${ }^{2}$ \\ ${ }^{1}$ Башкирский государственный университет, Уфа, 450076, Россия \\ ${ }^{2}$ Уфимский федеральный исследовательский центр РАН, Уфа, 450054, Россия
}

Актуальность исследуемой проблемы обусловлена увеличением количества полимерного мусора на основе синтетических полимеров, что определяет целесообразность его вовлечения в повторную переработку применительно к термопластичных полиолефинам. Значительная доля пластикового мусора приходится на пластмассовые изделия из полипропилена, при этом перерабатываемое сырье, практически всегда содержит смесь полипропилена с различным содержанием полиэтилена. Цель работы заключалась в изучение термических характеристик полимерных компаундов на основе вторичного полипропилена, наполненного полиэтиленом высокого и низкого давления. Ведущим подходом к исследованию данной проблемы является использование методов термогравиметрии и дифференциальной сканирующей калориметрии, позволяющих выявить закономерности изменения температурных и тепловых характеристик фазовых переходов, а также термической устойчивости полимерных компаундов. Показано, что наличие двух пиков плавления и кристаллизации на термограммах дифференциальной сканирующей калориметрии смесей полипропилен-полиэтилен указывает на несовместимость полимеров, при этом полимерная система является гетерофазной. В присутствии полиэтилена происходит изменение скорости кристаллизации полипропилена, при этом температура его плавления снижается, а температура кристаллизации увеличивается по сравнению с чистым полимером. Наполнение компаунда полиэтиленом как низкого, так и высокого давления снижает скорость разложения вторичного полипропилена и смещает процесс разложения компаундов 
в область более высоких температур. Масса сухого остатка при нагреве до $400^{\circ} \mathrm{C}$ и $600^{\circ} \mathrm{C}$ для полимерного компаунда с полиэтиленом низкого давления выше по сравнению с полиэтиленом высокого давления. Материалы статьи могут быть полезными для созданий полимерных композитов на основе вторичного полипропилена в присутствии полиэтилена, а также разработке технологических режимов их переработки.

Ключевые слова: вторичный полипропилен, полиэтилен низкого давления, полиэтилен высокого давления, дифференциальная сканирующая калориметрия, термогравиметрический анализ.

\section{1. Введение}

Разработка новых материалов из синтетических полимеров и расширение ассортимента пластмассовых изделий на их основе приводит к увеличению экологической нагрузки на окружающую среду ввиду длительного времени разложения таких веществ после выхода из эксплуатации и попадания в бытовой мусор [1-3]. Значительная доля пластикового мусора приходится на пластмассовые изделия из полипропилена, представляющего собой термопластичный полимер, годный для повторной переработки технологически простыми методами литья под давлением и экструзии [4-10]. Сырье, полученное в процессе сортировки и разделения пластикового мусора, практически всегда содержит смесь полипропилена с различным содержанием полиэтилена.

Предлагаются различные решения по повышению совместимости различных полимеров олефиновой группы, так в работе [11] рассмотрены закономерности формирования компаундов на основе вторичного полипропилена и полиэтилена высокого давления за счет введения в смесь цеолитов и катализаторов ЦиглераНатта, используемых как модификаторы полимерной структуры. Показано, что термическая обработка полимерных отходов в присутствии катализатора представляет потенциал для переработки полимерных материалов с высоким загрязнением другими полимерами и может генерировать вторичные материалы с улучшенными свойствами. С целью улучшения физикомеханических свойств компаундов на основе полипропилена и полиэтилена в работе [12] предложено использовать гамма-излучение, позволяющее увеличить ударную вязкость полимерного композита. Методом дифференциальной сканирующей калориметрии в [13] показано, что полиэтилен высокого и низкого давления по-разному влияют на скорость кристаллизации полимерной смеси с полипропиленом, при этом не отмечается отрицательного влияния состава компаунда на механические свойства. В работе [14] показано, что механические свойства смесей вторичного полиэтилена и вторичного полипропилена удается улучшить за счет использования добавок этилен-пропиленового каучука, выступающего в качестве компатибилизатора. Изучение закономерностей формирования композитов на основе вторичных полипропилена и полиэтилена с требуемыми физико-механическими свойствами является актуальной задачей в области вовлечения пластиковых отходов в повторную переработку.

Целью настоящей работы являлось изучение методом термогравиметрии и дифференциальной сканирующей калориметрии термических характеристик полимерных компаундов на основе вторичного полипропилена, наполненного полиэтиленом высокого и низкого давления.

\section{2. Методика эксперимента}

В работе использовали вторичный полипропилен (ПП) на основе некондиционных изделий из гомополимера полипропилена марки PP H350FF/3, производимых методом литья под давлением. В качестве наполнителя использовали полиэтилен низкого давления (ПНД) ГОСТ 16338-85, полиэтилен высокого давления (ПВД) ГОСТ 16337-77.

Приготовление компаундов вторичного полипропилена, наполненного полиэтиленом в объеме от 5 до 40 мас.\% проводили в смесительной камере пластографа Plastograph EC (Brabender, Германия) при температуре $180^{\circ} \mathrm{C}$, скорости вращения шнеков 30 об/мин в течение 15 мин при нагрузке $200 \mathrm{H}$.

Исследование теплофизических характеристик проводили методом дифференциальной сканирующей калориметрии (ДСК) на калориметре DSC 214 Polyma (NETZSH, Германия) в температурном диапазоне $30-200^{\circ} \mathrm{C}$ при скорости сканирования 10 град/мин. Метод ДСК-анализа позволяет определить температуру плавления $T_{\text {пл }}$ и кристаллизации $T_{\text {кр }}$, энтальпию плавления $\Delta H_{\text {пл }}$ и кристаллизации $\Delta H_{\text {кр }}$.

С целью изучения закономерностей термического разложения компаундов использовали термогравиметрический анализ (ТГА) с использованием термогравиметра TG 209 F1 Libra (NETZSCH, Германия) в интервале температур $25-1050^{\circ} \mathrm{C}$, при динамическом нагреве со скоростью $20^{\circ} \mathrm{C} /$ мин в среде азота. Для оценки термической устойчивости полимеров в работе использовали следующие характеристики: $T_{\text {н }}$ - температура начала разложения полимера, соответствующая началу снижения массы образца при нагревании; $T_{1}, T_{5}-$ температуры, соответствующие разложению полимера на $1 \%$ и $5 \%$ от первоначального значения массы; остаток после нагрева образца до температур $400^{\circ} \mathrm{C}$ и $600^{\circ} \mathrm{C}-$ параметры, которые использовались для характеристики процесса деструкции полимера и оценки наличия в полимере термически устойчивых примесей или добавок; $T_{\max }$ - температура, соответствующая максимальной скорости разложения полимера, определяемая максимумом на дифференциальной кривой термогравиметрического анализа (ДТГ).

\section{3. Обсуждение результатов}

На термограммах ДСК образцов чистого ПП и смесей полимеров ПП-ПНД, представленных на Рис. 1 и Рис. 2, 
в режиме нагрева фиксируются две температуры плавления, соответствующие каждому из полимерных компонентов: ПНД $\left(130.3-131.7^{\circ} \mathrm{C}\right)$ и ПП $\left(164.7-167.0^{\circ} \mathrm{C}\right)$ (Табл. 1). Значения $T_{\text {пл }}$ соответствующие ПНД в полимерных смесях, близки к аналогичному значению для исходного полимера $\left(131.0^{\circ} \mathrm{C}\right)$, тогда как для ПП значения $T_{\text {пл }}$ в смесях несколько ниже на $1.8-4.1^{\circ} \mathrm{C}$, чем у исходного ПП $\left(168.8^{\circ} \mathrm{C}\right)$, причем с увеличением содержания ПНД в смеси полимеров прослеживается тенденция к снижению $T_{\text {пл }}$, соответствующей ПП.

Верхняя кривая ДСК соответствуют выделению тепла образцом, а нижняя поглощению тепла в процессах нагрева и охлаждения материала.

На термограммах ДСК полимерных смесей с высоким содержанием ПНД наблюдается две температуры кристаллизации, соответствующие двум пикам каждого

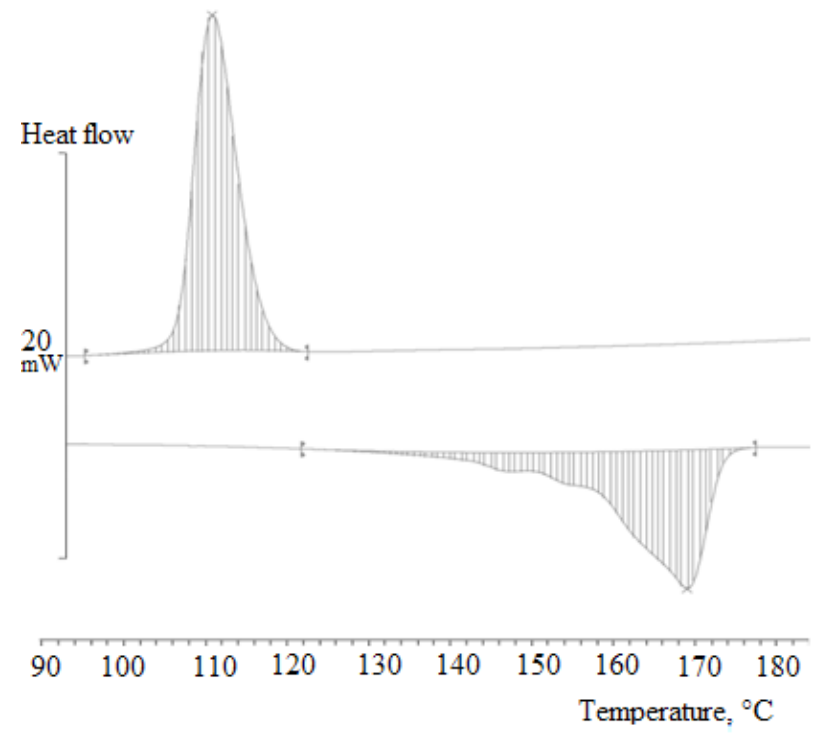

Рис. 1. Экспериментальная термограмма ДСК образца чистого ПП. Fig. 1. Experimental thermogram of a DSC sample of pure PP. компонента ПНД $\left(114.0-114.5^{\circ} \mathrm{C}\right)$ и ПП $\left(120.1-120.5^{\circ} \mathrm{C}\right)$. Следует отметить, что указанные значения $T_{\text {кр }}$ для ПП выше на $3.4-3.8^{\circ} \mathrm{C}$, чем значение этого параметра для исходного полимера $\left(116.7^{\circ} \mathrm{C}\right)$ (Табл. 1). По-видимому, наличие в смеси полиэтилена низкого давления приводит к смещению процесса (и температуры) кристаллизации в область более высоких температур. В данном случае объединения пиков, соответствующих кристаллизации каждого из полимеров не происходит, что указывает на несовместимость двух полимерных компонентов.

В зависимости от состава полимерной смеси наблюдается существенное изменение значений энтальпии плавления, соответствующих каждому полимерному компоненту. С увеличением содержания ПНД в смеси

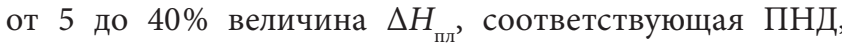
закономерно увеличивается с 3.8 до 48.1 Дж/г, тогда

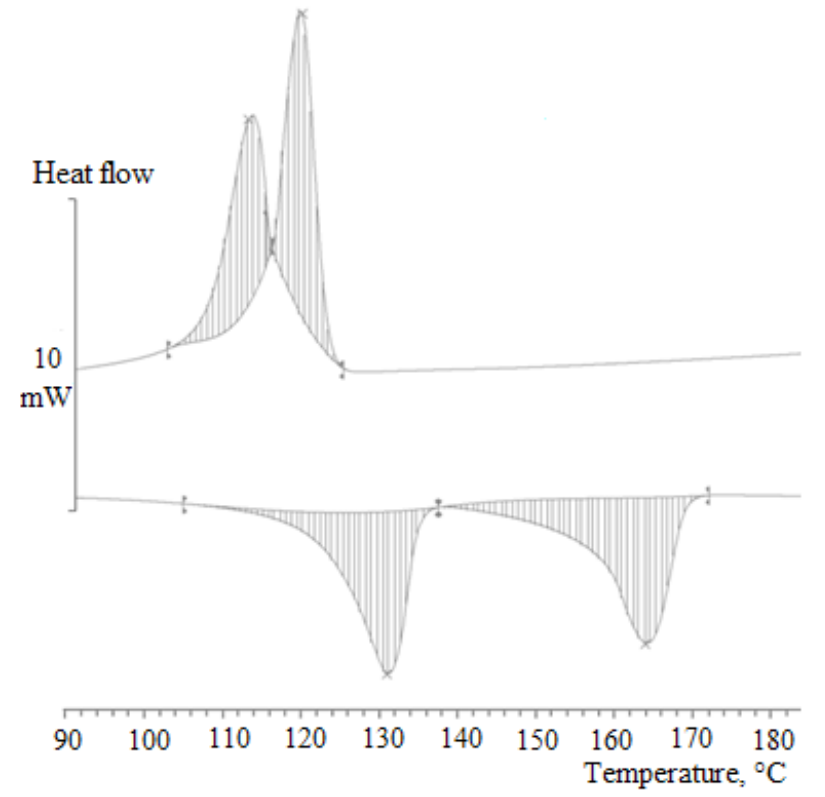

Рис. 2. Экспериментальная термограмма ДСК образца полимерного компаунда ПП 60\%-ПНД $40 \%$.

Fig. 2. Experimental thermogram of DSC sample of polymer compound PP $60 \%-H D P E 40 \%$.

Табл. 1. Результаты ДСК-анализа полимерных компаундов ПП-ПНД.

Table 1. Results of DSC analysis of PP-HDPE polymer compounds.

\begin{tabular}{|c|c|c|c|c|c|c|c|c|}
\hline \multirow{2}{*}{ Образец / Sample } & \multicolumn{2}{|c|}{$\begin{array}{l}T_{\text {плл }}{ }^{\circ} \mathrm{C} \\
T_{\mathrm{m}},{ }^{\circ} \mathrm{C}\end{array}$} & \multicolumn{2}{|c|}{$\begin{array}{c}\Delta H_{\text {плл }}, \text { Дж/г } \\
\Delta H_{\mathrm{m}}, \mathrm{J} / \mathrm{g} \\
\end{array}$} & \multicolumn{2}{|c|}{$\begin{array}{l}T_{\text {кр }},{ }^{\circ} \mathrm{C} \\
T_{c},{ }^{\circ} \mathrm{C} \\
\end{array}$} & \multicolumn{2}{|c|}{$\begin{array}{c}\Delta H_{\mathrm{xp}}, \text { Дж/г } \\
\Delta H_{\mathrm{c}}, \mathrm{J} / \mathrm{g} \\
\end{array}$} \\
\hline & 1 & 2 & 1 & 2 & 1 & 2 & 1 & 2 \\
\hline ПП / РР & - & 168.8 & - & -90.2 & & 116.7 & & 106.7 \\
\hline ПНД / HDPE & 131.7 & - & -96.2 & - & 114.0 & - & 50.6 & - \\
\hline $\begin{array}{l}95 \% \text { ПП + 5\% ПНД } \\
95 \% \text { РР + 5\% НDРЕ }\end{array}$ & 130.3 & 167.0 & -3.8 & -84.2 & \multicolumn{2}{|c|}{119.5} & \multicolumn{2}{|c|}{113.0} \\
\hline $\begin{array}{l}90 \% \text { ПП +10\% ПНД } \\
90 \% \text { РР +10\% НDРЕ }\end{array}$ & 131.2 & 167.0 & -8.5 & -76.3 & \multicolumn{2}{|c|}{120.0} & \multicolumn{2}{|c|}{111.0} \\
\hline $\begin{array}{l}80 \% \text { ПП +20\% ПНД } \\
80 \% \text { РР + 20\% НDPE }\end{array}$ & 131.2 & 166.0 & -22.1 & -65.4 & 114.5 & 120.5 & 6.2 & 55.0 \\
\hline $\begin{array}{l}60 \% \text { ПП + 40\% ПНД } \\
60 \% \text { РР + 40\% НDРЕ }\end{array}$ & 131.7 & 164.7 & -48.1 & -55.0 & 114.0 & 120.1 & 35.4 & 44.7 \\
\hline
\end{tabular}


как значение указанного параметра, соответствующее ПП, напротив, снижается с 84.2 до 55 Дж/г (Табл. 1).

Аналогичным образом изменяются энтальпии кристаллизации полимерных компонентов в смеси: с ростом содержания ПНД от 20 до $40 \%$ величина $\Delta H_{\text {кр }}$, соответствующая ПНД, увеличивается с 6.2 до 35.4 Дж/г, а параметр, соответствующий ПП, снижается с 55 до 44.7 Дж/г (Табл. 1).

Обратим внимание, что значение $\Delta H_{\text {кр }}$ компаунда с низким содержанием ПНД (5-10\%) даже несколько выше, чем у исходного ПП (Табл. 2).

На термограммах ДСК образцов смесей полимеров ПП-ПВД, представленных на Рис. 3, в режиме нагрева фиксируются две температуры плавления, соответствующие каждому из полимерных компонентов: ПВД $\left(105.5-106.5^{\circ} \mathrm{C}\right)$ и ПП $\left(164.5-166.3^{\circ} \mathrm{C}\right)$ (Табл. 2). Значения $T_{\text {пл, }}$ соответствующие ПВД в полимерных смесях, близки к аналогичному значению для исходного полимера $\left(106.0^{\circ} \mathrm{C}\right)$, тогда как для ПП значения $T_{\text {пл }}$ в смесях ниже на $2.5-4.3^{\circ} \mathrm{C}$, чем у исходного ПП $\left(168.8^{\circ} \mathrm{C}\right)$, причем с увеличением содержания ПВД прослеживается тенденция к снижению значения $T_{\text {пл }}$, соответствующего ПП в смеси полимеров.

На термограммах ДСК смеси ПП-ПВД с низким содержанием ПВД (5\%), представленных на Рис. 3, в режиме охлаждения фиксируется один пик и, соответственно, одна температура кристаллизации $\left(118.5^{\circ} \mathrm{C}\right)$. Для смесей с более высоким содержанием ПВД (10-40\%) наблюдается два пика и, соответственно, две температуры кристаллизации для каждого из полимерных компонентов: ПВД $\left(90.0-90.5^{\circ} \mathrm{C}\right)$ и ПП $\left(118.0-118.8^{\circ} \mathrm{C}\right)($ Табл. 2$)$.

Следует отметить, что указанные значения $T_{\text {кр }}$ для ПП в смеси выше на $1.3-2.1^{\circ} \mathrm{C}$, чем значение этого параметра для исходного полимера $\left(116.7^{\circ} \mathrm{C}\right)$ (Табл. 2). Обратим внимание, что подобная картина наблюдается и для смесей ПП-ПНД, но для рассматриваемых смесей

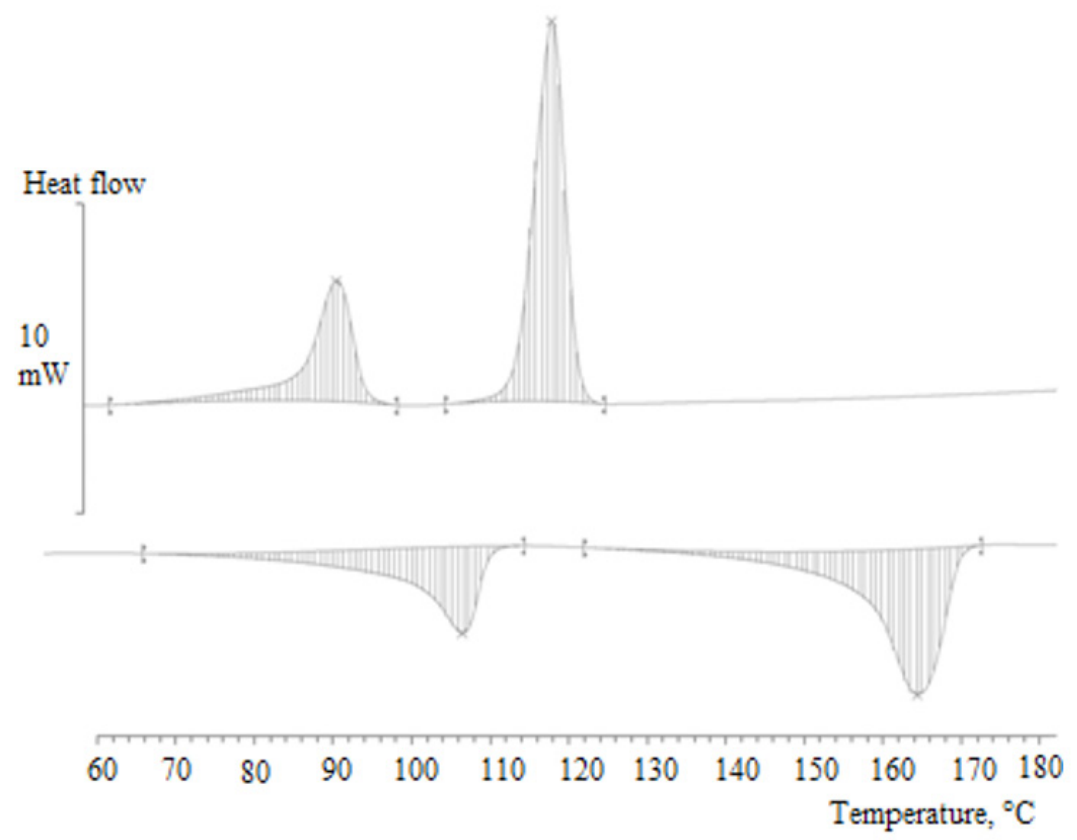

Рис. 3. Экспериментальная термограмма ДСК образца полимерного компаунда ПП 60\%-ПВД 40\%.

Fig. 3. Experimental thermogram of DSC sample of polymer compound PP 60\%-LDPE $40 \%$.

Табл. 2. Результаты ДСК-анализа полимерных компаундов ПП-ПВД.

Table 2. Results of DSC analysis of PP-LDPE polymer compounds.

\begin{tabular}{|c|c|c|c|c|c|c|c|c|}
\hline \multirow{2}{*}{ Образец / Sample } & \multicolumn{2}{|c|}{$\begin{array}{l}T_{\text {пл, }}{ }^{\circ} \mathrm{C} \\
T_{\mathrm{m}},{ }^{\circ} \mathrm{C} \\
\end{array}$} & \multicolumn{2}{|c|}{$\begin{array}{c}\Delta H_{\text {пл }}, \text { Дж/г } \\
\Delta H_{\mathrm{m}}, \mathrm{J} / \mathrm{g} \\
\end{array}$} & \multicolumn{2}{|c|}{$\begin{array}{l}T_{\text {кр }},{ }^{\circ} \mathrm{C} \\
T_{c},{ }^{\circ} \mathrm{C} \\
\end{array}$} & \multicolumn{2}{|c|}{$\begin{array}{c}\Delta H_{\mathrm{kp}}, \text { Дж/г } \\
\Delta H_{\mathrm{c}}, \mathrm{J} / \mathrm{g}\end{array}$} \\
\hline & 1 & 2 & 1 & 2 & 1 & 2 & 1 & 2 \\
\hline ПВД / LDPE & 106.0 & - & -84.6 & - & 90.5 & - & 45.8 & - \\
\hline $\begin{array}{l}95 \% \text { ПП + 5\% ПВД } \\
95 \% \text { РР + 5\% LDPE }\end{array}$ & 105.5 & 166.3 & -1.0 & -77.6 & 90.3 & 118.5 & 0.7 & 93.3 \\
\hline $\begin{array}{l}90 \% \text { ПП +10\% ПВД } \\
90 \% \text { PР +10\% LDPE }\end{array}$ & 106.2 & 165.3 & -3.2 & -83.1 & 90.2 & 118.8 & 3.1 & 95.1 \\
\hline $\begin{array}{l}80 \% \text { ПП + 20\% ПВД } \\
80 \% \text { PР + 20\% LDPE }\end{array}$ & 106.3 & 165.7 & -12.4 & -80.5 & 90.0 & 118.5 & 9.0 & 87.9 \\
\hline $\begin{array}{l}60 \% \text { ПП + 40\% ПВД } \\
60 \% \text { PР + 40\% LDPE }\end{array}$ & 106.5 & 164.5 & -34.3 & -55.7 & 90.5 & 118.0 & 29.5 & 65.5 \\
\hline
\end{tabular}


ПП-ПВД смещение $T_{\text {кр }}$ ПП происходит в меньшей степени, что следует связывать, вероятно, с меньшей температурой кристаллизации ПВД $\left(T_{\text {кр }}=90.5^{\circ} \mathrm{C}\right)$.

В зависимости от состава полимерной смеси наблюдается изменение значений энтальпии плавления, соответствующих каждому полимерному компоненту. С увеличением содержания ПНД в смеси от 5 до 40\%

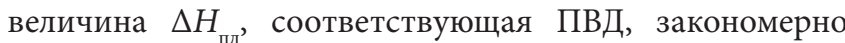
увеличивается с 1.0 до 34.3 Дж/г, тогда как значение указанного параметра, соответствующее ПП, напротив, снижается с 77.6 до 55.7 Дж/г, причем указанные зависимости являются линейными (Табл. 2).

Аналогичным образом изменяется энтальпия кристаллизации полимерной смеси: с ростом содержания

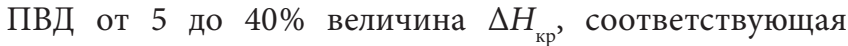
ПВД, увеличивается с 0.5 до 29.5 Дж/г, а параметр $\Delta H_{\text {кр' }}$ соответствующий ПП, снижается с 93.3 до 65.5 Дж/г (Табл. 2), причем характер изменения $\Delta H_{\text {кр }}$ полимерных компонентов смеси близок к линейному. Значение $\Delta H_{\text {кр }}$ рассмотренных компаундов ПП-ПВД ниже, чем исходного ПП (Табл. 2).

Методом термогравиметрического анализа установлено, что исходный ПП характеризуется несколько более высокой температурой начала разложения $T_{\text {н }}$ $\left(235^{\circ} \mathrm{C}\right)$ по сравнению с ПНД и компаундами, на основе этих полимеров $\left(T_{\mathrm{H}}=217-223^{\circ} \mathrm{C}\right)$ (Табл. 3). Вместе с тем, значения параметров $T_{1}$ и $T_{5}$ для компаундов и исходного ПП отличаются несущественно. Следовательно, введение в полипропилен до $40 \%$ мас. ПНД не оказывает заметного влияния на термостабильность компаунда.

Сравнительная оценка параметров термического разложения опытных образцов ПП-ПНД показала (Табл. 3), что масса остатка после нагрева компаунда до температуры $400^{\circ} \mathrm{C}$ увеличивается пропорционально содержанию ПНД в смеси с 6.9\% при содержании ПНД в компаунде $5 \%$ до $36.4 \%$ при содержании ПНД 40\%. С увеличением содержания ПНД в смеси наблюдается повышение массы остатка после нагрева компаунда до температуры $600^{\circ} \mathrm{C}$, что указывает на увеличение содержания в полимерном образце термически стабильных примесей, не разлагающихся при высоких температурах. Происходит смещение пиков на кривых ДТГ компаундов, характеризующих максимальную скорость разложения ( $T_{\max }$ на ДТГ), в область более высоких температур на $33-45^{\circ} \mathrm{C}$, по сравнению с исходным ПП. Следует отметить, что указанное смещение значений температур $T_{\max }$ на кривой ДТГ не зависит от содержания ПНД в смеси (Табл. 3).

По данным Табл. S1 (дополнительный материал), можно установить, что исходный ПП характеризуется несколько более высокой температурой начала разложения $T_{\text {н }}\left(235^{\circ} \mathrm{C}\right)$ по сравнению с ПВД и компаундами, на основе этих полимеров $\left(T_{\text {н }}=205-221^{\circ} \mathrm{C}\right)$. Вместе с тем, значения параметров $T_{1}$ и $T_{5}$ для компаундов и ПП отличаются не столь существенно. Следовательно, введение ПВД, по крайней мере, до содержания 40\%, не оказывает существенного влияния на термостабильность компаунда.

Сравнительная оценка параметров термического разложения ПП и компаундов ПП-ПВД, представленных в Табл. S1 и на Рис. S1 (дополнительный материал), показала, что масса остатка после нагрева компаунда до температуры $400^{\circ} \mathrm{C}$ увеличивается пропорционально содержанию ПВД в смеси с 5.7\% при содержании ПВД в компаунде 5\% до 19.5\% при содержании ПВД 40\%. Происходит смещение пиков на кривой ДТГ, характеризующих максимальную скорость разложения компаунда ( $T_{\max }$ на ДТГ), по сравнению с исходным ПП в область более высоких температур на $20-40^{\circ} \mathrm{C}$, причем указанное смещение (значение температур $T_{\max }$ на кривой ДТГ) практически не зависит от содержания ПВД в смеси.

Полученные результаты исследовательской работы могут быть полезными для созданий полимерных композитов на основе вторичного полипропилена в присутствии полиэтилена, а также разработке технологических режимов их переработки различными методами.

\section{4. Выводы}

1. В присутствии полиэтилена температура плавления полипропилена по сравнению с чистым полимером снижается на $1.8-4.1^{\circ} \mathrm{C}$ для полиэтилена низкого

Табл. 3. Результаты ТГА-анализа полимерных компаундов ПП-ПНД.

Table 3. Results of TGA analysis of PP-HDPE polymer compounds.

\begin{tabular}{|c|c|c|c|c|c|c|c|}
\hline \multirow{2}{*}{ Образец / Sample } & \multirow{2}{*}{$\begin{array}{l}T_{\mathrm{H}},{ }^{\circ} \mathrm{C} \\
T_{\mathrm{b}},{ }^{\circ} \mathrm{C}\end{array}$} & \multirow{2}{*}{$T_{1},{ }^{\circ} \mathrm{C}$} & \multirow{2}{*}{$T_{5},{ }^{\circ} \mathrm{C}$} & \multicolumn{2}{|c|}{$\begin{array}{l}\text { Остаток, \% } \\
\text { Remains, \% } \\
\end{array}$} & \multicolumn{2}{|c|}{$\begin{array}{c}T_{\max } \text { на ДТГ, }{ }^{\circ} \mathrm{C} \\
T_{\max } \text { on DTG, }{ }^{\circ} \mathrm{C} \\
\end{array}$} \\
\hline & & & & $\begin{array}{c}\text { при } 400^{\circ} \mathrm{C} \\
\text { at } 400^{\circ} \mathrm{C}\end{array}$ & $\begin{array}{c}\text { при } 600^{\circ} \mathrm{C} \text { at } \\
600^{\circ} \mathrm{C} \\
\end{array}$ & 1 & 2 \\
\hline ПП / РР & 235 & 254 & 269 & 4.54 & 1.79 & 320 & 454 \\
\hline $\begin{array}{l}\text { 95\% ПП + 5\% ПНД } \\
95 \% \text { РР + 5\% НDРЕ }\end{array}$ & 223 & 251 & 269 & 6.91 & 2.96 & 358 & 470 \\
\hline $\begin{array}{l}90 \% \text { ПП +10\% ПНД } \\
90 \% \text { РР + 10\% НDРЕ }\end{array}$ & 221 & 251 & 271 & 7.99 & 3.30 & 364 & 468 \\
\hline $\begin{array}{l}80 \% \text { ПП + 20\% ПНД } \\
80 \% \text { РР + 20\% НDРЕ }\end{array}$ & 219 & 252 & 274 & 10.46 & 4.38 & 365 & 475 \\
\hline $\begin{array}{l}60 \% \text { ПП + 40\% ПНД } \\
60 \% \text { РР + 40\% НDРЕ }\end{array}$ & 217 & 255 & 284 & 36.41 & 6.71 & 353 & 452 \\
\hline
\end{tabular}


давления и на $2.5-4.3^{\circ} \mathrm{C}$ для полиэтилена высокого давления, при этом температура кристаллизации полипропилена в смеси выше аналогичной величины для чистого полимера на $3.4-3.8^{\circ} \mathrm{C}$ для полиэтилена низкого давления и на $1.3-2.1^{\circ} \mathrm{C}$ для полиэтилена высокого давления.

2. Наполнение компаунда полиэтиленом как низкого, так и высокого давления увеличивает его термическую стабильность за счет смещения максимальной скорости разложения основной массы образца в область высоких температур на $33-45^{\circ} \mathrm{C}$ для полиэтилена низкого давления и на $20-40^{\circ} \mathrm{C}$ для полиэтилена высокого давления, а также снижения количества разложившегося полимера при нагреве до $600^{\circ} \mathrm{C}$.

Дополнительньй материал/Supplementary material. Электронная версия статьи содержит дополнительный материал, доступный безвозмездно на сайте журнала (lettersonmaterials.com). / The online version of this paper contains supplementary material available free of charge at the journal's Web site (lettersonmaterials.com).

Благодарности/Acknowledgements. Работа выполнена при финансовой поддержке РФФИ, проект № 20-33-90052 и государственного задания FJWU-2020-0027 (на изготовление полимерных композитов). / The work was carried out with the financial support of the RFBR, project No. 20-33-90052 and the state task FJWU-2020-0027 (for the manufacture of polymer composites).

\section{Литература/References}

1. A. Nasir, T. Yasin, A. Islam. Journal of Applied Polymer Science. 119 (6), 3315 (2011). $\underline{\text { Crossref }}$
2. R. V. Camargo, C. Saron. Journal of Polymers and the Environment. 28 (3), 794 (2020). Crossref

3. R.B. Salikhov, M.V. Bazunova, A.A. Bazunova, T. R. Salikhov, V.P. Zakharov. Letters on Materials. 8 (4), 485 (2018). Crossref

4. L. Canopoli, F. Coulon, S. T. Wagland. Science of the Total Environment. 698, 134125 (2020). Crossref

5. R. J. Tapper, M.L. Longana, H. Yu, I. Hamerton, K. D. Potter. ECCM 2018 - 18th European Conference on Composite Materials. 1, 43 (2018).

6. M. Spoerk, F. Arbeiter, I. Raguž, C. Holzer, J. GonzalezGutierrez. Polymers. 11 (8), 1318 (2019). Crossref

7. E. Silva Barbosa Ferreira, C.H. Ó Pereira, E. M. Araújo, E. B. Bezerra, D.D. Siqueira, R. M. R. Wellen. Materials Research. 22, 20180850 (2019). Crossref

8. B. Hansen, C. Borsoi, M. A. Dahlem Júnior, A. L. Catto. Industrial Crops and Products. 140, 111696 (2019). Crossref

9. R. Y. Lazdin, V.P. Zakharov, A. S. Shurshina, E. I. Kulish. Letters on Materials. 9 (1), 70 (2019). (in Russian) [Р.Ю. Лаздин, В.П. Захаров, А.С. Шуршина, Е.И. Кулиш. Письма о материалах. 9 (1), 70 (2019).] Crossref

10. S.A. Stoian, A.R. Gabor, A.-M. Albu, C.A. Nicolae, V. Raditoiu, D. M. Panaitescu. Journal of Thermal Analysis and Calorimetry. 138 (4), 2469 (2019). rossref

11. R. V. Camargo, C. Saron. Journal of Polymers and the Environment. 28 (3), 794 (2020). Crossref

12. W. Wang, X. Zhang, Z. Mao, W. Zhao. Results in Physics. 12, 2169 (2019). Crossref

13. C. Aumnate, N. Rudolph, M. Sarmadi. Polymers. 11 (9), 1456 (2019). Crossref

14. E. Gazo-Hanna. Journal of engineering science and technology. 12 (2), 87 (2019). Crossref 